\title{
Melt transport rates in heterogeneous mantle beneath mid-ocean ridges
}

\author{
Samuel M. Weatherley ${ }^{\mathrm{a}, 1, *}$, Richard F. Katz ${ }^{\mathrm{a}}$ \\ ${ }^{a}$ Department of Earth Sciences, University of Oxford, South Parks Road, Oxford. OX1 3AN. UK
}

\begin{abstract}
Recent insights to melt migration beneath ridges suggest that channelized flow is a consequence of melting of a heterogeneous mantle, and that spreading rate modulates the dynamics of the localized flow. A corollary of this finding is that both mantle heterogeneity and spreading rate have implications for the speed and time scale of melt migration. Here, we investigate these implications using numerical models of magma flow in heterogeneous mantle beneath spreading plates. The models predict that a broad distribution of magma flow speeds is characteristic of the sub-ridge mantle. Within the melting region, magmatic flow is fastest in regions of average fusibility; surprisingly, magmas from sources of above-average fusibility travel to the ridge in a longer time. Spreading rate has comparatively simple consequences, mainly resulting in faster segregation speeds at higher spreading rates. The computed time scales are short enough to preserve deep origin ${ }^{230} \mathrm{Th}$ disequilibria and, under favourable parameter regimes, also ${ }^{226}$ Ra excesses. An important prediction from the models is that mantle heterogeneity induces significant natural variability into U-series disequilibria, complicating the identification of relationships between disequilibria and ridge properties or chemical signatures of heterogeneity.
\end{abstract}

Keywords: U-series disequilibria, mid-ocean ridge basalt, mantle heterogeneity, melt

\footnotetext{
*Corresponding author

Email addresses: smw@geus.dk (Samuel M. Weatherley), richard.katz@earth.ox.ac.uk (Richard F. Katz)

${ }^{1}$ Present address: GEUS, Geological Survey of Denmark and Greenland, Øster Voldgade 10, 1315 Copenhagen K. Denmark. Tel: +4591333868
} 
migration, mantle melting, pyroxenite

\section{Introduction}

Chemical heterogeneity in Earth's mantle induces local and regional perturbations in the fusibility and melting rate beneath oceanic volcanoes. For example, regions enriched in subducted oceanic lithosphere start to melt at deeper depths and with higher melt productivity than mantle peridotite (Hirschmann and Stolper, 1996), whereas other regions are so refractory, and contribute so little to the genesis of magmas, that they are essentially unsampled by mid-ocean ridge basalts (Liu et al., 2008). In two recent numerical studies Weatherley and Katz (2012) and Katz and Weatherley (2012) considered the effect that mantle heterogeneity has on the dynamics of melt migration beneath oceanic volcanoes. Their models suggest that (i) heterogeneity causes magma to localize into a network of high porosity channels, and (ii) that the topology of the channel network depends on the spatial arrangement of mantle heterogeneity. Channelised flow is often invoked to explain the major and trace element characteristics of oceanic basalts and mantle rocks (e.g. Kelemen et al., 1995, 1997), and to explain geochemical evidence for rapid magma flow speeds in the mantle (see reviews by Lundstrom et al., 2005; Elliott and Spiegelman, 2014). In this paper we explore the prediction arising from Weatherley and Katz (2012) and Katz and Weatherley (2012) that mantle heterogeneity has important but as yet unrecognized consequences for the time scales of melt migration beneath oceanic volcanoes.

Temporal constraints on magma flow in the mantle largely are derived from observations of U-series disequilibria in very young or zero age MORB. Specifically, disequilibria provide temporal constraints on combined melt generation and transport processes that have occurred within approximately 5 half-lives of the shorted-lived nuclide in a parent-daughter nuclide pair. For understanding magma flow processes, the most useful nuclides are ${ }^{230} \mathrm{Th},{ }^{231} \mathrm{~Pa},{ }^{226} \mathrm{Ra}$ and ${ }^{210} \mathrm{~Pb}$; these decay with half-lives of c. $75 \mathrm{ka}, 33 \mathrm{ka}$, $1.6 \mathrm{ka}$ and $22 \mathrm{yr}$. Since a wide range of processes can generate U-series disequilbria, models are often used to explore the implications of disequilibria for the time scale of 
melt migration in the mantle. In a review of existing attempts to model U-series melting models, Elliott and Spiegelman (2014) note that models generally require a large set of assumptions such as melt-mineral partition coefficients, mantle porosity, source mineralogy and petrology, the way in which melt is organized in the mantle, and the location and mechanism of chemical fractionation. Unsurprisingly, the combined outcome of these models is rather complex. Interpretations of ${ }^{230} \mathrm{Th}$ disequilibria suggest that the mean flow speed between the melt source and ridge axis is around $1 \mathrm{~m} / \mathrm{yr}$, and shorter lived ${ }^{226} \mathrm{Ra}$ disequilibria can be interpreted to require speeds $>50 \mathrm{~m} / \mathrm{yr}$ (Rubin and MacDougall, 1988; Kelemen et al., 1997; McKenzie, 2000; Stracke et al., 2006; Turner and Bourdon, 2010). These speeds are fast enough to require magma flow by some form of channelised melt transport. However, existing models of chanelized flow appear to be incapable of reproducing the ${ }^{210} \mathrm{~Pb}$ disequilibria signatures observed by Rubin et al. (2009), thus ${ }^{210} \mathrm{~Pb}$ deficits are unexplained by current theories of channelized melt migration.

How U-series disequilibria in MORB relate to chemical signatures of mantle heterogeneity is the focus of only a small number of investigations. In a study of the Southeast Indian Ridge, Russo et al. (2009) investigated nonsystematic geographic variation of U-series disequilibria with axial depth, crustal thickness and ridge morphology. The authors explain the observations by along-axis variation in the melt supply, which they suggest is a response to long wavelength temperature gradients and small variations in source heterogeneity. Several other studies note a weak, positive correlation in noisy data between the amplitude of ${ }^{230} \mathrm{Th}$ disequilibria and enrichment of the source in incompatible elements (Lundstrom et al., 1995; Lundstrom, 2000; Elliott and Spiegelman, 2003; Kokfelt et al., 2003; Koorneef et al., 2012). Since Th and U are fractionated more strongly in the presence of garnet, one explanation for this trend is that larger amplitude disequilibria result from a relatively larger proportion of melt originating in the garnet stability field (Lundstrom et al., 1998). Yet, as Russo et al. (2009) demonstrate, it is non-trivial to make an explicit connection between the amplitude of disequilibria and magmas from garnet-bearing source rocks. Furthermore, it is unclear how the 
dynamics and time scale of magma flow might contribute to the observed signals.

The current dynamical understanding of melt migration is founded on mathematical theories and numerical models for the physics of magma flow in porous, compactible mantle rock (McKenzie, 1984; Fowler, 1985; Ribe, 1985; Bercovici et al., 2001). A goal for many models of magma flow is to explore and understand the dynamics of melt localization. Among these, channel formation is attributed to the reaction infiltration instability (Ortoleva et al., 1987) that in the context of melt migration, describes a positive feedback between magma flux and dissolution of porous mantle rock. This feedback causes a net transfer of mass from the solid mantle to the magma, locally increasing the porosity and melting rate, and results in the formation of channels (Kelemen, 1990; Kelemen et al., 1995; Aharonov et al., 1995). As a consequence, models of this process must treat the physics and thermochemistry of magma flow as a coupled system. For simplicity, previous studies generally restrict the problem to magma flow in an upwelling column of partially melting mantle rock, neglect conservation of energy and parameterise melting using kinetic theory (Spiegelman et al., 2001; Spiegelman and Kelemen, 2003; Liang and Guo, 2003; Liang et al., 2010; Schiemenz et al., 2011; Hesse et al., 2011).

Other models by Katz (2008, 2010), Hewitt (2010), Weatherley and Katz (2012) and Katz and Weatherley (2012) differ by adopting an energetically consistent approach to melting. These models capture the onset of partial melting and suggest that latent heat effects suppress the emergence of channels in the situation of magma flow through a chemically homogenous mantle. However, models by Weatherley and Katz (2012) and Katz and Weatherley (2012) show that channels emerge in a heterogeneous mantle, where spatial variations in composition are considered to be synonymous with variations in the fusibility of mantle rock. Weatherley and Katz (2012) shows that more fusible heterogeneities melt preferentially, and that the resulting flux of magma can be sufficient to nucleate high porosity channels. In a companion study, Katz and Weatherley (2012) considers the effect of different topologies of mantle heterogeneity and plate spreading on melt migration; they find that both heterogeneity and plate spreading have important 
consequences for the arrangement of channels and delivery of melt to the ridge axis.

In this contribution we extend the models of Katz and Weatherley (2012) to quantify the effect of source heterogeneity and spreading rate on the speed and time scale of melt migration. Section 2 outlines the theory and numerical model of magma flow in heterogeneous mantle rock, summarises the petrological system (which is a key component of the model) and provides details on the approach used to determine the speed and time scale of melt migration. Solutions to the numerical experiments are presented in section 3. Results are presented in dimensional form. Those presented at the start of the section aim to characterise the time scales and flow speeds predicted by the models, while those at the end of the section illustrate the effect of heterogeneity. The results are discussed in section 4, where particular attention is paid to how the time scale of melt migration depends on spreading rate and mantle heterogeneity. A scaling analysis explores how the results might change under different parameter regimes; the assumptions and limitations inherent in the models are also noted. The section concludes with a discussion on the implications of the results for our understanding of U-series disequilibria in MORB, including tentative prediction of their covariance with source composition.

\section{The model}

\subsection{Model configuration}

The situation we consider is of magma flow, melting and melt-rock interaction in passively flowing, compositionally heterogeneous mantle beneath mid-ocean ridges (figure 1). Subsolidus mantle rock flows into the bottom of the domain, upwells and melts adiabatically, and the melt then makes its way towards the surface where it is erupted or freezes into the lithosphere. Previous models by Katz (2008, 2010) and Katz and Weatherley (2012) form the basis for those presented here, although they are modified in order to derive the predictions of the speed and time scale of melt migration beneath ridges. A brief summary of the behaviour predicted by the model is given in section 3.1 . 


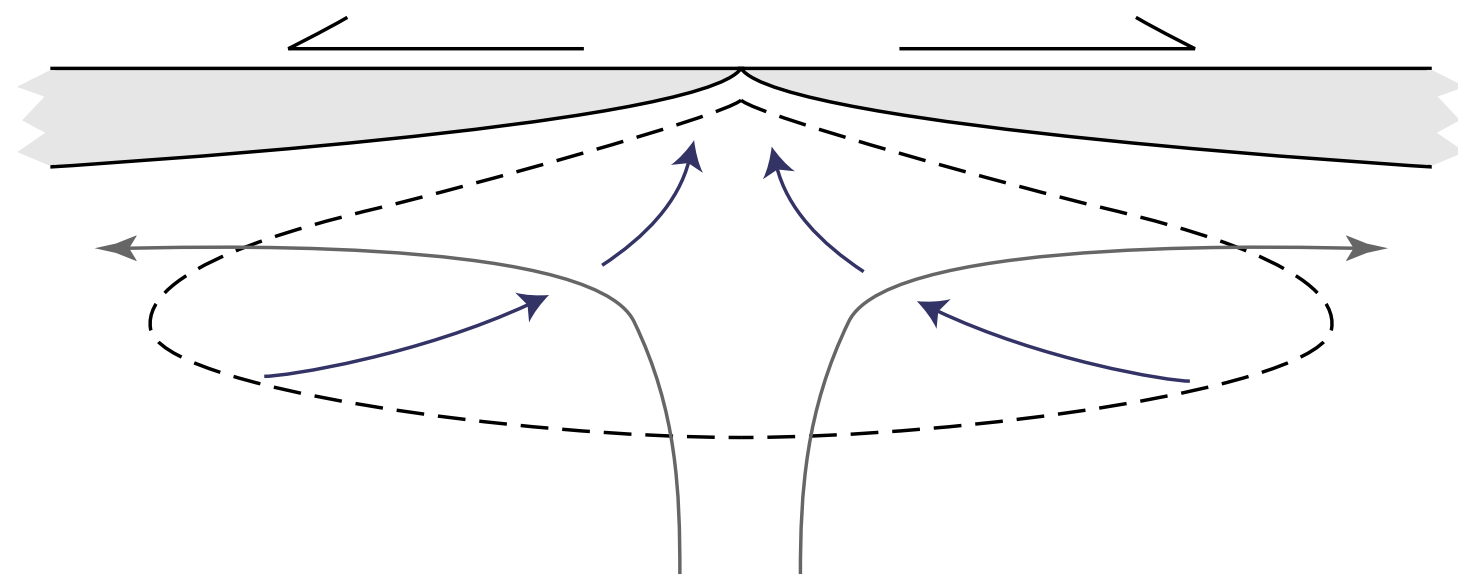

Figure 1: A schematic illustration of the model setup. Lithospheric plates (light grey regions) spread apart at a known rate, driving large scale flow in the solid mantle (dark grey arrows). Decompression causes the mantle to melt within an unknown region indicated by the dashed line. Within this region solid rock and magma coexist and the melt segregates by porous flow (blue arrows)

The models solve equations for conservation of mass, momentum, composition and energy in a thermally and chemically diffusive system with two phases and two thermodynamic components. In other words, they seek solutions for the coupled dynamics of solid mantle rock and liquid magma, and employ a basic petrological model to allow for melting and freezing. In the model framework mantle rock is considered to be a compactible, crystalline solid that deforms by creeping flow; magma is modelled as a low viscosity liquid that migrates by porous flow. In partially molten regions, the magma and mantle are assumed to coexist and interpenetrate (McKenzie, 1985; Fowler, 1985 Ribe, 1985; Bercovici et al., 2001). The boundary conditions for the models are identical to those used by Katz (2010), the only difference being that the internal boundary condition for melt extraction is pinned to the apex of the melting region, rather than to the boundary at the mid-line of the domain. Full details for this condition are provided in Weatherley (2013). An additional deviation between the models here and previous variants is that mantle flow is considered to be a passive response to plate spreading; variation in the gravitational body force on the two-phase aggregate is neglected. The equations are discretized using a finite volume approach on a staggered mesh with 


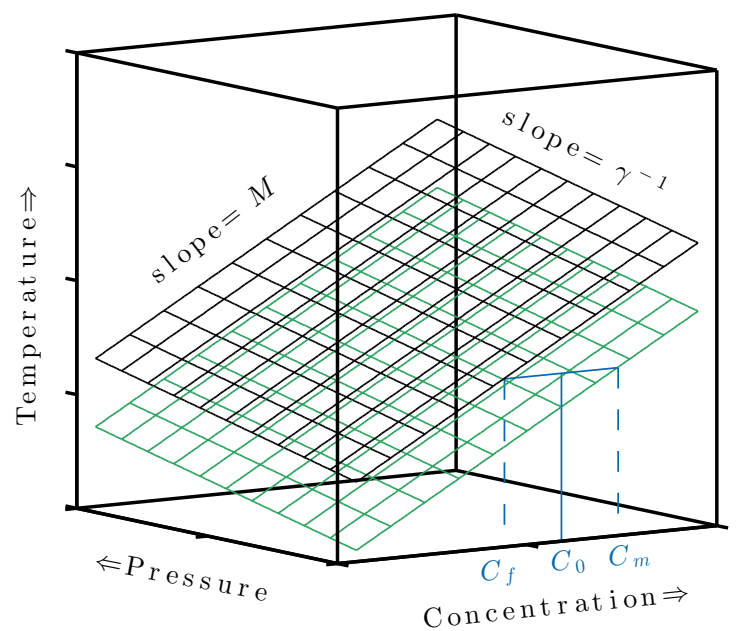

Figure 2: A binary solid solution with linearized solidus (lower surface, green lines) and liquidus (upper surface, black lines) constitutes the phase diagram. $C_{0}$ marks the bulk composition at zero pressure, $C_{f}$ and $C_{m}$ indicate the compositions of coexisting magma and rockm also at zero pressure. The mass fraction of the liquid is $\left(C_{0}-C_{f}\right) /\left(C_{m}-C_{f}\right)$.

$1.25 \mathrm{~km}$ grid spacing in each direction. The governing equations are solved using the method described by Katz and Weatherley (2012).

\subsection{Phase relations and mantle heterogeneity}

Mass transfer between the solid and liquid by melting and freezing is an important feature of the model. To allow for this, we follow the examples of Ribe (1985); Katz (2008, 2010); Hewitt (2010); Katz and Weatherley (2012) and Weatherley and Katz (2012) and assume that coexisting rock and magma are in local thermodynamic equilibrium. An important consequence of this assumption is that magma and mantle rock are in local chemical and thermal equilibrium in all partially molten regions. A simple phase diagram (figure 2) comprising two components of different fusibility describes the petrological system. At every time step the phase diagram is applied in each grid cell in order to relate the bulk composition, bulk enthalpy, and lithostatic pressure to the temperature, phase compositions, and rate of mass transfer between rock and magma. Since the phase diagram corresponds only to a hypothetical, highly simplified petro- 

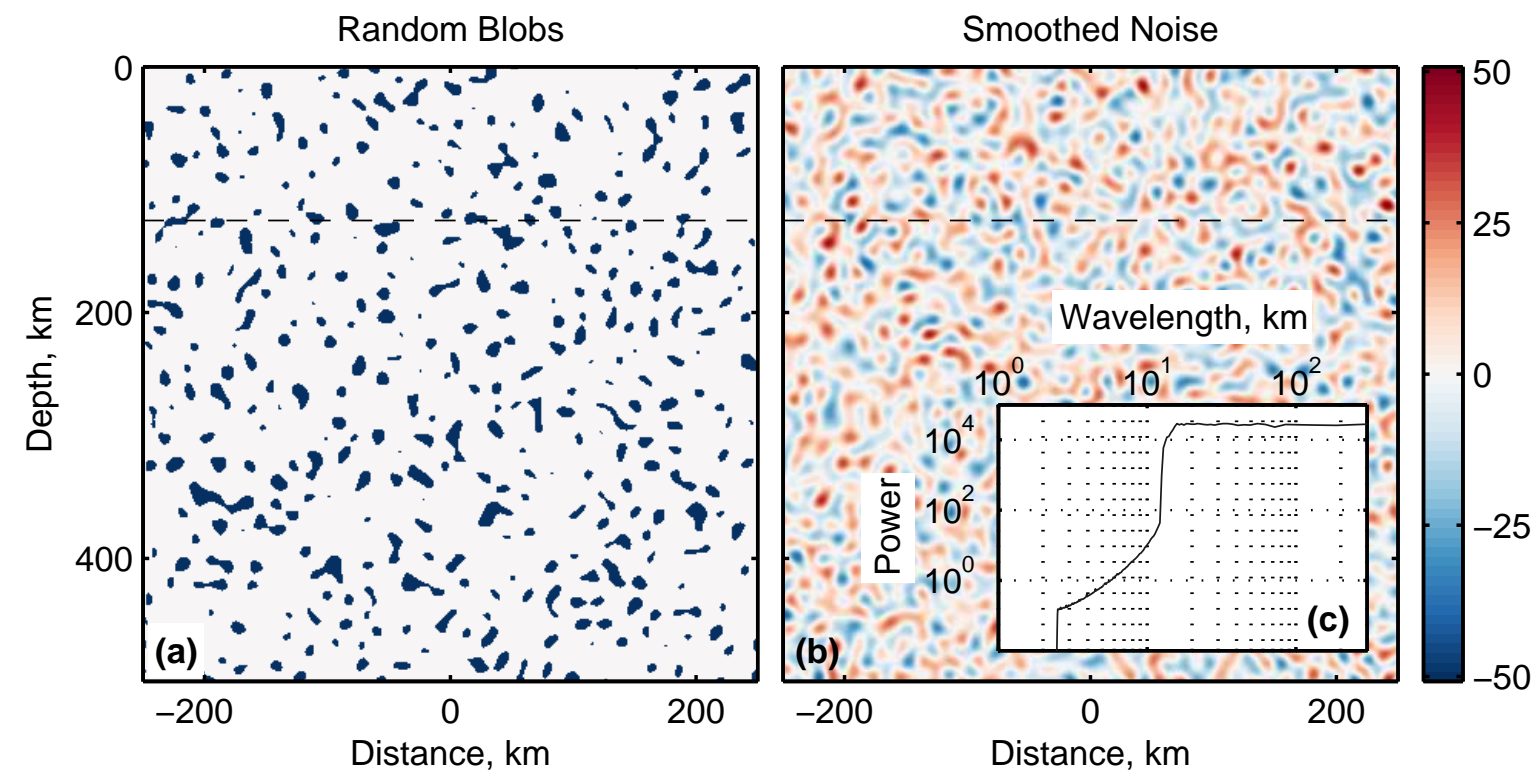

Figure 3: The compositional heterogeneity fields used to initialize the models, shown as a perturbation to the solidus temperature, $\Delta T_{C}=M_{S}\left(C_{m}-C_{0}\right) . C_{0}=0.5$ for both fields. Dashed lines in (a) and (b) show the size of the computational domain relative to the heterogeneity fields. The heterogeneity fields are larger in the $z$-direction in order to evolve the bottom boundary condition on $C$ as material is advected into the domain. (a) 'Random blob' style heterogeneity . $10 \%$ of the area is occupied by more fusible material. (b) 'Smoothed noise' type heterogeneity. (c) Directionally averaged power spectrum for the heterogeneity field in panel (b). It shows approximately uniform power for wavelengths $>11$ $\mathrm{km}$ and greatly reduced power for shorter wavelengths.

logic system, compositional variations are expressed in terms of their perturbation to the solidus temperature relative to a reference composition, or equivalently referred to here as fusibility. This is expressed as $\Delta T_{C}=M\left(C_{m}-C_{0}\right)$, where $M$ is the slope $\partial T / \partial C$ of the solidus, $C_{m}$ is the local composition of the mantle rock and $C_{0}$ is a reference composition.

Figures $3 \mathrm{a}$ and $3 \mathrm{~b}$ show the two contrasting heterogeneity fields used to initialize the models. They are constructed using stochastic algorithms that generate spatial variations in the ratio of the two thermodynamic components. Full details of the algorithms are provided in Katz and Weatherley (2012). In figure 3a, the 'random blob' 
heterogeneity model consists of randomly shaped, isolated regions that are uniformly enriched in the more fusible component. Prior to the onset of melting, the enriched regions perturb the local solidus temperature by $-50 \mathrm{~K}$, have a characteristic size of $10 \mathrm{~km}$ and occupy an area fraction of 0.1 . The composition of the non-enriched matrix defines $C_{0}$. The 'smoothed noise' model (figure $3 \mathrm{~b}$ ) is produced by allowing the ratio of the components to vary smoothly and continuously over all wavelengths greater than a specified cut-off. The spectrum has equal power at all wavelengths greater than $10 \mathrm{~km}$ and negligible power for wavelengths $<5 \mathrm{~km}$ (figure 3c). Prior to the onset of melting, $\Delta T_{C}$ varies by up to $\pm 50 \mathrm{~K}$ and $C_{0}$ is set to the 2 -norm of the heterogeneity field. The inspiration for these conjectural descriptions of mantle heterogeneity lies in (a) recognition that regions of the mantle enriched in ancient oceanic crust are more fusible than those that are not (Hirschmann and Stolper, 1996), and that the mantle contains refractory domains that are essentially unsampled by melting beneath oceanic volcanoes (Liu et al., 2008), (b) uncertainty surrounding the lithology of mantle heterogeneity, and whether recycled oceanic crust melts and enriches the surrounding mantle prior to the main melting event beneath ridges (e.g. Yaxley and Green, 1998), (c) uncertainty in the topology of heterogeneity (Allègre and Turcotte, 1986; Kellogg and Turcotte, 1990), (d) analyses of scattered seismic waves that suggest chemically distinct heterogeneities with length scales of around $10 \mathrm{~km}$ exist in the mantle (Kaneshima and Helffrich, 1999 , 2003), (e) geochemical estimates that the MORB source region contains around 10\% recycled oceanic crust (e.g. Wood, 1979; Sobolev et al., 2008; Shorttle and Maclennan, 2011), and (f) the need to represent mantle heterogeneity on scales larger than the grid resolution of the simulations $(1.25 \mathrm{~km})$.

\subsection{Determination of melt migration timescale}

To determine the speed and duration of melt migration predicted by the model, the domain is seeded with Lagrangian particles that track the motion of individual fluid parcels. The magma velocity is given by

$$
\mathbf{v}_{f}=\mathbf{v}_{m}-\frac{K}{\phi \mu}\left[\nabla P_{d}+\Delta \rho \mathbf{g}\right],
$$


where $K=k_{0} \phi^{n}$ is permeability ( $k_{0}$ is the permeability coefficient, $\phi$ is porosity and $n$ is the permeability exponent) $\mu$ is the viscosity of the magma, $P_{d}$ is the dynamic fluid pressure, $\Delta \rho$ is the density difference between the solid mantle and liquid magma and $g$ is the acceleration due to gravity. Equation 1 states that the velocity of the magma depends on the matrix velocity, dynamic pressure gradients, and buoyancy forces that are modulated by permeability and the viscosity of the magma. The tracer particles are defined to be perfectly incompatible; they are released from the solid at the onset of melting, can be re-incorporated into the solid by freezing, and can exit the domain at the ridge axis. The particles are accurately tracked by updating their positions at each time step in a two stage process. First the velocity field is linearly interpolated to the position of each particle. Then using the interpolated velocity, the position of each particle is updated over one half of a time step. The process is then repeated and the tracer particles are moved over the remaining half of the time step.

The tracer particles are initialized by placing one in the centre of every grid cell. As the particles move through the domain, they record at every time step their velocity, position, the porosity and composition of the matrix within their host grid cell, and the model time. Those that exit the domain at the ridge axis are filtered to exclude any that $(i)$ are not initialized in subsolidus mantle for which the degree of melting is zero, and $(i i)$ are refrozen into the matrix at any point between the melt source and the ridge axis. Data from particles that pass through this filter are used to compute the duration and speed of melt migration. In subsolidus regions, the motion of the tracer particles is equal to the solid mantle flow field. Since the flow field approximates the corner flow solution, the upwelling rate is fastest directly beneath the ridge axis and slower in the flanking regions (Batchelor, 1967). On long time scales a consequence of this is that the rate of delivery of tracer particles to the melting region is uneven across its width. To reduce any sampling bias the tracer particles are reinitialized periodically on a time scale of $350 \mathrm{kyr}$. Particles are not reinitialized more frequently, since magma migrating to the ridge on shorter time scales are capable of preserving ${ }^{230} \mathrm{Th}$ disequilibria generated at the base of the melting region. 


\section{Results}

\subsection{Overview of dynamics}

This study is based around three suites of numerical experiments. One suite is initialized with a chemically homogenous mantle, another with the random blob heteroegenity model (figure 3a), and the final suite with the smoothed-noise heterogeneity model (figure $3 \mathrm{~b}$ ). Each suite comprises four simulations with half-spreading rates $U_{0}$ of $2,4,6$, and $8 \mathrm{~cm} / \mathrm{yr}$. Some key aspects of the model behaviour are outlined below, but the reader is referred to Katz and Weatherley (2012) for a complementary description and analysis.

Figure 4 illustrates the basic dynamical behaviour of the system with a snapshot from a simulation run with no initial heterogeneity and a half spreading rate of $4 \mathrm{~cm} / \mathrm{yr}$. Models run with a homogenous mantle do not predict channelized flow; instead melt migrates by dynamically stable, diffuse porous flow. Melting is confined to a roughly triangular-shaped region extending about $75 \mathrm{~km}$ deep into the mantle and over $100 \mathrm{~km}$ to either side of the ridge axis. Throughout this region, coexisting magma and mantle rock are in local chemical and thermodynamic equilibrium (section 2.2). Compaction maintains the porosity at low values, typically around $<1 \%$. However, the porosity varies systematically throughout the melting region, largely as a response to the pattern of mantle upwelling; porosity is largest directly beneath the ridge axis where the rate of mantle upwelling (and decompression) is greatest, and decreases towards the flanks of the melting region. This porosity distribution sets the overal pattern of melt migration towards the ridge axis. Within c. $30 \mathrm{~km}$ either side of the spreading axis, melts are focused to the ridge axis by buoyancy and lateral pressure gradients, agreeing with predictions by Spiegelman and McKenzie (1987) and Yinting et al. (1991). At distances greater than $30 \mathrm{~km}$, the mode of melt focusing resembles the model by Sparks and Parmentier (1991), in which magma rises vertically to the base of the lithosphere, and then uphill along the top of the melting region to the ridge axis.

In numerical experiments initialised with a heterogeneous mantle, magma flow lo- 

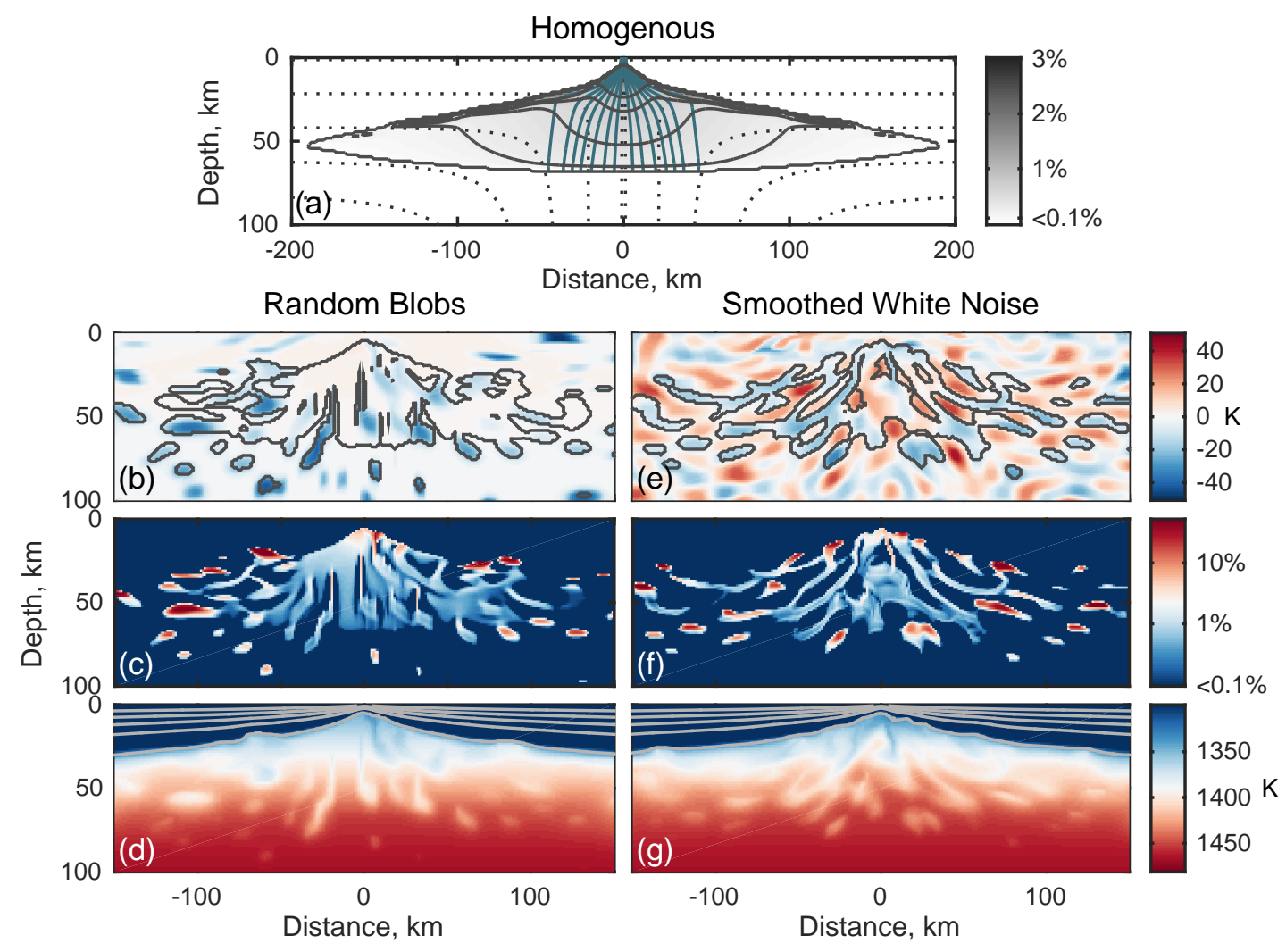

Figure 4: Snapshots from representative simulations run with contrasting styles of mantle heterogeneity. In each case the half spreading rate is $4 \mathrm{~cm} / \mathrm{yr}$ and the model time is 1.9 Ma. Panel (a) shows results from a simulation run with a homogenous mantle. Colours and solid dark grey contour lines show the porosity and extent of the melting region; the dotted streamlines show the solid mantle flow field; the solid blue-green lines plot the trajectories of some tracer particles that travel to the ridge axis. Panels (b)-(d) show results from a simulation with the random blob type heterogeneity, and panels (e)-(g) show results from a simulation run with the smoothed noise heterogeneity. Panels (b) and (e) express mantle heterogeneity as a perturbation to the solidus (grey line) temperatures, (c) and (f) show porosity, and d and g show temperature. The solid grey lines contour temperatures between $0^{\circ} \mathrm{C}$ and $1300^{\circ} \mathrm{C}$. The models are subject to the parameter regime outlined in table A1. 
calizes into high porosity channels. Figure 4 shows snapshots of the matrix composition (figure $4 \mathrm{~b}, \mathrm{e}$ ), porosity (figure $4 \mathrm{c}, \mathrm{f}$ ) and temperature ((figure $4 \mathrm{~d}, \mathrm{~g}$ ) from representative experiments with $U_{0}=4 \mathrm{~cm} / \mathrm{yr}$. In these simulations, the arrangement of channels and dynamics of focusing strongly depend on the topology of mantle heterogeneity. In the random blob experiments (figures $4 \mathrm{~b}, \mathrm{c}, \mathrm{d}$ ) some channels are narrow and vertical, while others coincide with smeared-out heterogeneities. Melt focusing to the ridge axis is realised partly through channelized flow, and partly by flow along the lithosphere-asthenosphere boundary. In the smoothed noise experiment (figures 4 4 , f, g) channels are wider and focus magma to the ridge axis more efficiently. Channels are deflected around less fusible regions of the mantle, and tend to coincide with compositions that lie between the average mantle and those moderately enriched in the more fusible component. Although coexisting magma and mantle rock are in local chemical and thermal equilibrium in all partially molten regions, significant chemical disequilibrium can exist between magmas within channels and magmas outside of channels. This is because the timescale for melt transport through channels is much shorter than the timescale for diffusive equilibration of the channel and host mantle (Spiegelman and Kenyon, 1992).

In these examples, variation of porosity within the melting region is a consequence of combined mechanical (compaction) and thermodynamic (melting and freezing) effects. Weatherley and Katz (2012) showed that the melting rate $\Gamma$ can be expressed as the sum of contributions from mantle upwelling, reactive flow and thermal diffusion. The melting rate is such that in a homogenous mantle, mantle upwelling accounts for over $95 \%$ of the total melting rate. But in a heterogeneous mantle where flow is channelized, upwelling can account for a minor fraction of the total melting rate (as small as $20 \%$ in simulations by Weatherley and Katz (2012)), with the remained realised through reactive dissolution and thermal diffusion. Thus porosity variations in a heterogeneous mantle are largely a response to local thermodynamic effects. 


\subsection{Duration and distance of melt migration}

Figure 5 plots the time taken for tracer particles to travel from the base of the melting region to the ridge axis as a function of the distance that they travel. The duration of melt migration for any tracer particle is also referred to as the travel time, $\tau$, and the distance travelled by tracer particles $d$ is interchangeably referred to as the path length. These quantities are defined as

$$
\begin{gathered}
\tau=t_{\text {exit }}-t_{\text {release }}, \\
d=\int_{t, \text { release }}^{t, \text { exit }}\left|\mathbf{v}_{f}(t)\right| \mathrm{d} t,
\end{gathered}
$$

where $t_{\text {release }}$ is the time at which a particle is released for the first time from the solid by melting and $t_{\text {exit }}$ is the time at which the same particle exits the melting region at the ridge axis.

Figure 5 a shows results from experiments initialised with a homogeneous mantle; the travel time increases approximately linearly with the path length and is shorter when the spreading rate is fast. Path lengths range from $50-75 \mathrm{~km}$ when $U_{0}=2 \mathrm{~cm} / \mathrm{yr}$ to $55-95 \mathrm{~km}$ when $U_{0}=8 \mathrm{~cm} / \mathrm{yr}$. For each experiment the range of travel times is approximately $150 \mathrm{kyr}$, and decreases from 200-350 kyr when $U_{0}=2 \mathrm{~cm} / \mathrm{yr}$ to 90 $240 \mathrm{kyr}$ when $U_{0}=8 \mathrm{~cm} / \mathrm{yr}$. The arrays of data are more densely populated with tracer particles representing shorter path lengths and travel times since the upwelling rate is fastest and porosity is highest directly beneath the ridge axis. The spreading rate dependence of travel time is discussed more fully in section 4.1 .

Figures $5 \mathrm{~b}$ and $5 \mathrm{c}$ show results from experiments run with the random blob and smoothed noise heterogeneity models. To leading order, these data show the same trends as experiments with a homogenous mantle (fig. 5a); the travel time increases with path length and decreases with spreading rate. However, the data in figures $5 \mathrm{~b}, \mathrm{c}$ exhibit much scatter and the correlation between path length and travel time is weaker. Compared to results from the homogenous case, the data span a wider range of travel times and path lengths. For a half spreading rate of $2 \mathrm{~cm} / \mathrm{yr}$, the range of travel times 


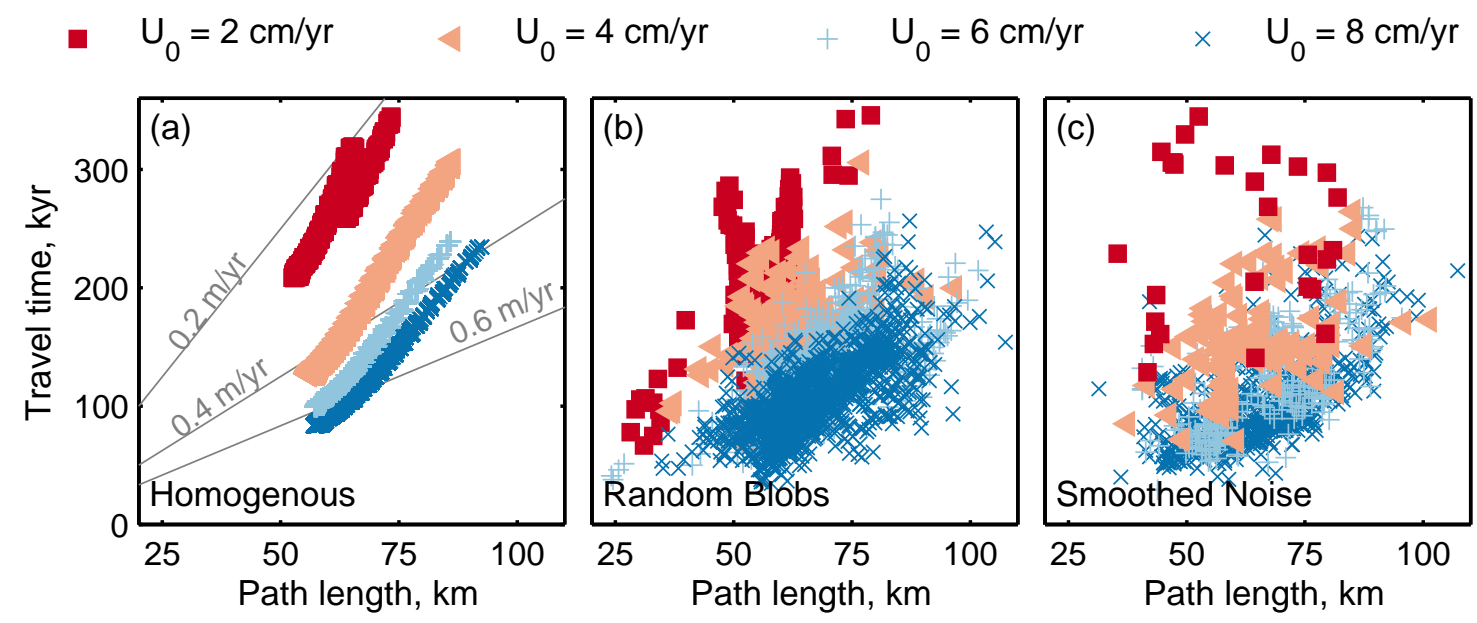

Figure 5: Travel time for individual particles plotted as a function of path length for half-spreading rates $U_{0} 2,4,6$, and $8 \mathrm{~cm} / \mathrm{yr}$. Panel (a) shows data from simulations with a homogenous mantle. Grey lines correspond to the magma flow speeds indicated. The number of particles reaching the ridge axis $n$ in each simulation, arranged in order of increasing $U_{0}$ is $2168,6663,11765$ and 17821 . Panel (b) shows data from simulations where the heterogeneity is manifested as random blobs. For these simulations $n=363,805,1380$ and 1828. Panel (c) plots data from simulations run with smoothed noise heterogeneity. For these runs $n=30,103,278$ and 575 . 
is approximately 50-350 kyr and path lengths span 25-80 km; for $U_{0}=8 \mathrm{~cm} / \mathrm{yr}$ travel times span 25-300 kyr and path lengths range between $25 \mathrm{~km}$ and $110 \mathrm{~km}$. The arrays of data in figures $5 \mathrm{~b}, \mathrm{c}$ are more densely populated for intermediate path lengths and travel times. They show that the duration of melt migration is shorter in the channelized flow regime by around 10-20\%. The sensitivity of these results to the parameter regime for the model and discussion on their correspondence to $\mathrm{U}$-series disequilbria is presented in sections 4.3 and 4.5 .

\subsection{Speed}

Figure 6 shows normalized histograms of the particle mean speed for each of the numerical experiments presented in figure 5. The mean speed for particle $p$ is defined as $\left\langle v_{p}\right\rangle=\tau_{p} / d_{p}$, where $\tau_{p}$ and $d_{p}$ are the particle-specific travel times and path lengths defined in equations 2 and 3 . Figures $6 \mathrm{a}-\mathrm{d}$ show data from experiments run with a homogenous mantle. These histograms have a strong negative skew, revealing that particles with the fastest speeds are the most abundant. From figure $5 \mathrm{a}$ it is evident that the fastest particles are generally associated with shorter travel times and path lengths. The mode of the binned data increases with spreading rate from $0.20-0.25 \mathrm{~m} / \mathrm{yr}$ at $U_{0}=2 \mathrm{~cm} / \mathrm{yr}$ to $0.65-0.70 \mathrm{~m} / \mathrm{yr}$ when $U_{0}=8 \mathrm{~cm} / \mathrm{yr}$. The range of mean particle speeds also increases with spreading rate from $10 \mathrm{~cm} / \mathrm{yr}$ when $U_{0}=2 \mathrm{~cm} / \mathrm{yr}$ to $35 \mathrm{~cm} / \mathrm{yr}$ when $U_{0}=8 \mathrm{~cm} / \mathrm{yr}$.

Results in figures $6 \mathrm{e}-\mathrm{h}$ and $6 \mathrm{-}-\mathrm{l}$ correspond to experiments run with the random blob and smoothed noise heterogeneity models. These histograms have variable, positive skew and show a factor of $\sim 2$ increase on the range of mean particle speeds predicted by experiments run without mantle heterogeneity. Mean particle speeds range from 0-0.6 m/yr when $U_{0}=2 \mathrm{~cm} / \mathrm{yr}$ to $0.15-1.3 \mathrm{~m} / \mathrm{yr}$ when $U_{0}=8 \mathrm{~cm} / \mathrm{yr}$ (figures 6e -1 ). Generally, histograms for the smoothed noise cases have a more irregular structure than for those corresponding to experiments run with the random blob heterogeneity model. The mode of the binned, mean particle speeds is approximately independent of the presence or topology of mantle heterogeneity. 


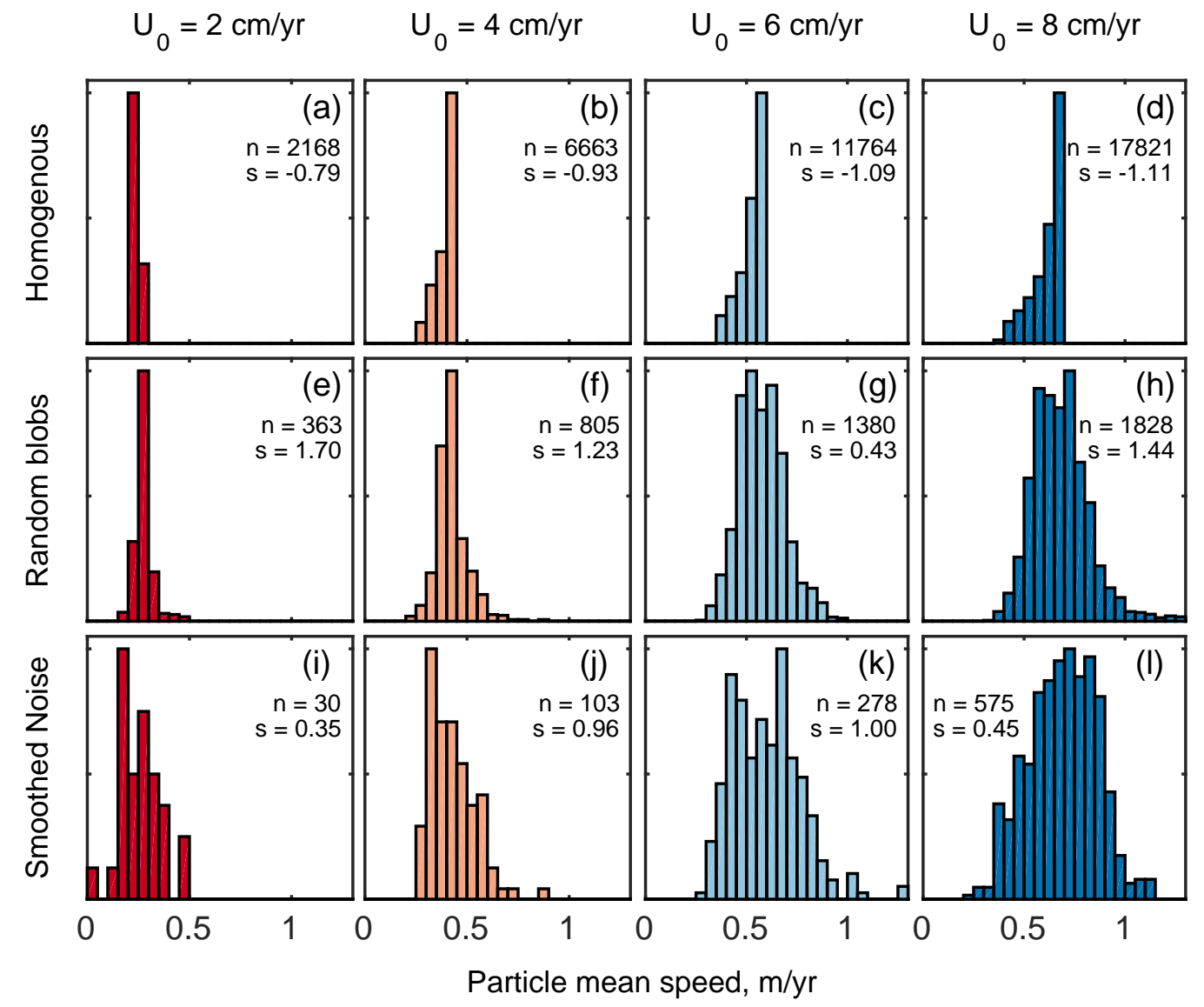

Figure 6: Normalized histograms showing the local mean speeds of particles. Each column shows results from simulations with the same half-spreading rate and each row presents data from simulations with different styles of heterogeneity as the initial condition. Bin widths are $5 \mathrm{~cm} / \mathrm{yr}, n$ is the number of data points contained within the histogram, and $s$ is is an estimate of the population skewness.

\subsection{Effect of composition}

Figure 7 reveals the effect that the source fusibility at the on set of melting, $\Delta T_{C}$, has on the duration and speed of melt migration. Data are taken from experiments run with the smoothed noise heterogeneity model only.

Figure $7 \mathrm{a}$ shows that the path length correlates negatively with $\Delta T_{C}$. This negative correlation is a consequence of the fact that more fusible rocks (more negative $\left.\Delta T_{C}\right)$ start to melt deeper. The combined effects of the shape of the melting region, channelized flow, and mantle heterogeneity mean that a range of path lengths can be 
associated with any given composition. Data are distributed relatively evenly across source compositions between $-20^{\circ} \mathrm{C} \leq \Delta T_{C} \leq 20^{\circ} \mathrm{C}$ but are less abundant for more extreme values. Figure $7 \mathrm{~b}$ shows that to leading order, the travel time and source compositions are related by a weak to moderate negative correlation for half spreading rates of 4,6 , and $8 \mathrm{~cm} / \mathrm{yr}$, although no correlation is evident for $U_{0}=2 \mathrm{~cm} / \mathrm{yr}$. The leading order trend arises from more fusible heterogeneities melting at deeper depth, while the weak correlation implies that the connectivity of channels and permeability structure does not vary systematically with source composition.

Figure $7 \mathrm{f}$ plots the mean particle speed against $\Delta T_{C}$. Although no obvious trend relates the two quantities, it can be seen that mean speeds are slower for regions where the fusibility perturbations are large $\left(\left|\Delta T_{C}\right|>20^{\circ} \mathrm{C}\right)$ and faster where fusibility is perturbed to a lesser extent. This result reinforces the implication from figure $7 \mathrm{~b}$ of non-systematic variations in permeability structure and channel connectivity.

To complement these data, the speed and composition for each particle were sampled at intervals of about 1000 years after the onset of melting to give the instantaneous speed and instantaneous composition. These results, shown in figure $7 \mathrm{~d}$, exhibit negligible correlation between speed and composition along trajectories of tracer particles. However, the greatest range and fastest speeds are observed in regions where mantle heterogeneity perturbs the solidus temperature between $-15^{\circ} \mathrm{C}$ and $+10^{\circ} \mathrm{C}$. In these regions, instantaneous speeds are, in some instances, as fast as $30 \mathrm{~m} / \mathrm{yr}$, but are often as low as a few decimetres per year. For more extreme compositions, the range and magnitude of instantaneous speeds is much reduced. In these regions the maximum magma speeds are around $2 \mathrm{~m} / \mathrm{yr}$, but the vast majority of tracers passing through more highly enriched and depleted regions have speeds of a few centimetres to a few tens of centimetres per year. 


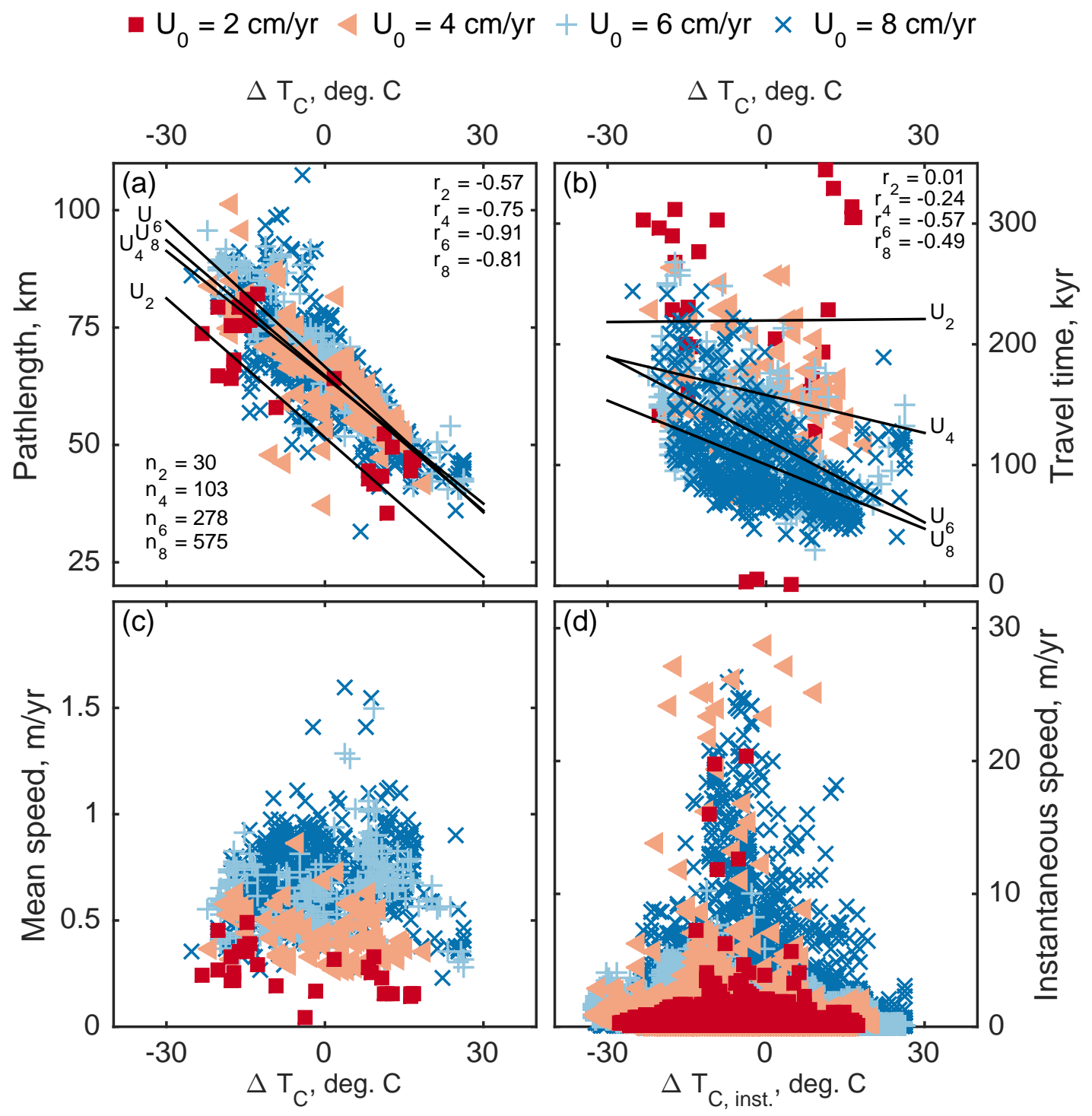

Figure 7: Effect of composition on the time scale and speed of melt migration for experiments run with the smoothed noise heterogeneity model. (a) Variation of travel time with source composition $\Delta T$. Black lines show least squares best fit lines for the different simulations and are labeled as $\mathrm{U}_{x}$, where $x$ is the half spreading rate in $\mathrm{cm} / \mathrm{yr}$. The corresponding sample correlation $r$ for each of the best fit lines is given in the upper right of the figure, and $n_{x}$ is the number of data points from each simulation. (b) Path length as a function of source composition, with black lines as for panel (a). Panel (c) plots mean particle speed as a function of source composition; panel (d) shows variation of the instantaneous speed with instantaneous composition, $\Delta T_{C \text {,inst. }}$, expressed in terms of a perturbation in solidus temperature. The sampling interval is approximately 1000 years. 


\section{Discussion}

\subsection{Effects of plate spreading rate}

Two leading-order trends emerge in the results: that shorter melt-transport path lengths and faster spreading rates are both associated with shorter durations of melt migration. These trends arise because plate spreading confines melting to a roughly triangular-shaped region of non-constant porosity. Analysis of the governing equations in 1D by Hewitt (2010) reveals that the magma speed $w$ scales with $W^{1-1 / n}$, where $W$ is the upwelling rate of the matrix and $n$ is the permeability exponent (Bear, 1972 , Turcotte and Schubert, 2002: Costa, 2006). For mantle convection patterns resembling corner flow, the half spreading rate defines a reference upwelling rate $W_{0}=3 / 2 U_{0}$ (Batchelor, 1967), thus $w \propto U_{0}^{1-1 / n}$. Figure 8 shows that this scaling accounts for the spreading rate dependance of the travel time in a homogenous mantle. In the experiment with $U_{0}=2 \mathrm{~cm} / \mathrm{yr}$, tracers associated with short path lengths $(d<65 \mathrm{~km})$ have anomalously slow speeds. This is a consequence of the slow upwelling causing smaller melting rates, lower porosity, lower permeability, and hence slower segregation.

\subsection{Effects of heterogeneity}

Compared to plate spreading, mantle heterogeneity has a more complicated effect on melt migration. While the fact that less fusible mantle melts at shallower depths readily explains the negative correlation between travel time and source composition, the relationship between speed and composition is more difficult to understand. To help explore why faster speeds are associated with source and regions where perturbations to the fusibility are relatively minor $\left(\left|\Delta T_{C}\right|<20^{\circ} \mathrm{C}\right.$, figures $7 \mathrm{k}$, d), figure 9 compares the spatial covariation of mantle heterogeneity with porosity for a representative experiment run with $U_{0}=6 \mathrm{~cm} / \mathrm{yr}$ and the smoothed-noise heterogeneity model. In panels a and c, black lines contour porosities $>1 \%$ to roughly show the location of channels and magma ponds. In this experiment, channels are confined, more or less, to the region within $100 \mathrm{~km}$ of the spreading axis and depths $<60 \mathrm{~km}$. The channels accommodate the fastest magma speeds (figure $9 \mathrm{~d}$ ) and broadly coincide with mantle of intermediate 


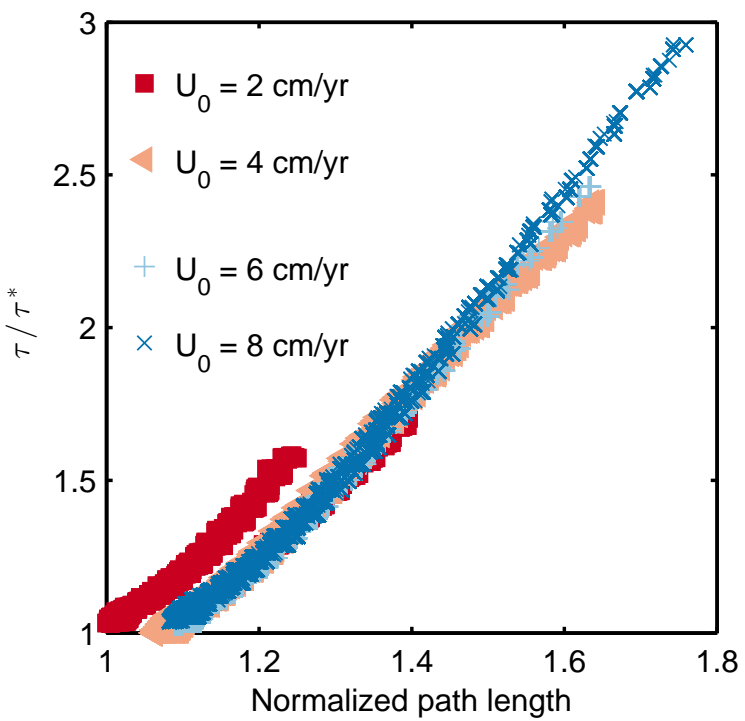

Figure 8: Scaled travel time versus nondimensional distance for the experiments conducted with no mantle heterogeneity. Travel time $\tau$ is scaled by $\tau^{*}=\left(3 / 2 U_{0}\right)^{1-1 / n} / l$, where $l$ is a characteristic length scale.

fusibility $\left(-15 \mathrm{~K} \leq \Delta T_{C} \leq+10 \mathrm{~K}\right)$; in regions of more extreme fusibility the flow speeds are slower. This correlation is also evident in figure $7 \mathrm{~d}$.

This relationship between composition and magma speed is a consequence of the energetics of melting. The imposition of local thermodynamic equilibrium pins the temperature of partially molten regions to the solidus temperature. Thus heat diffuses away from locally depleted regions into the surrounding more fusible and cooler mantle. In the most depleted regions $\left(\Delta T_{C} \geq 10 \mathrm{~K}\right)$, therefore, melting is suppressed, porosity is destroyed by compaction and the resulting small permeability accommodates slow instantaneous magma speeds and acts to decrease the mean speeds of magmas originating in these regions. Flow speeds in the most enriched regions $\left(\Delta T_{C} \leq-15 \mathrm{~K}\right)$ are slow for a different reason: enriched heterogeneities start to melt before the surrounding mantle and are surrounded by a halo of impermeable mantle rock. This prevents magma from flowing into the channel network; within the heterogeneity the magma speed $\left|\mathbf{v}_{f}\right|$ approximates the mantle speed $\left|\mathbf{v}_{m}\right|$, which results in slow instantaneous and mean 

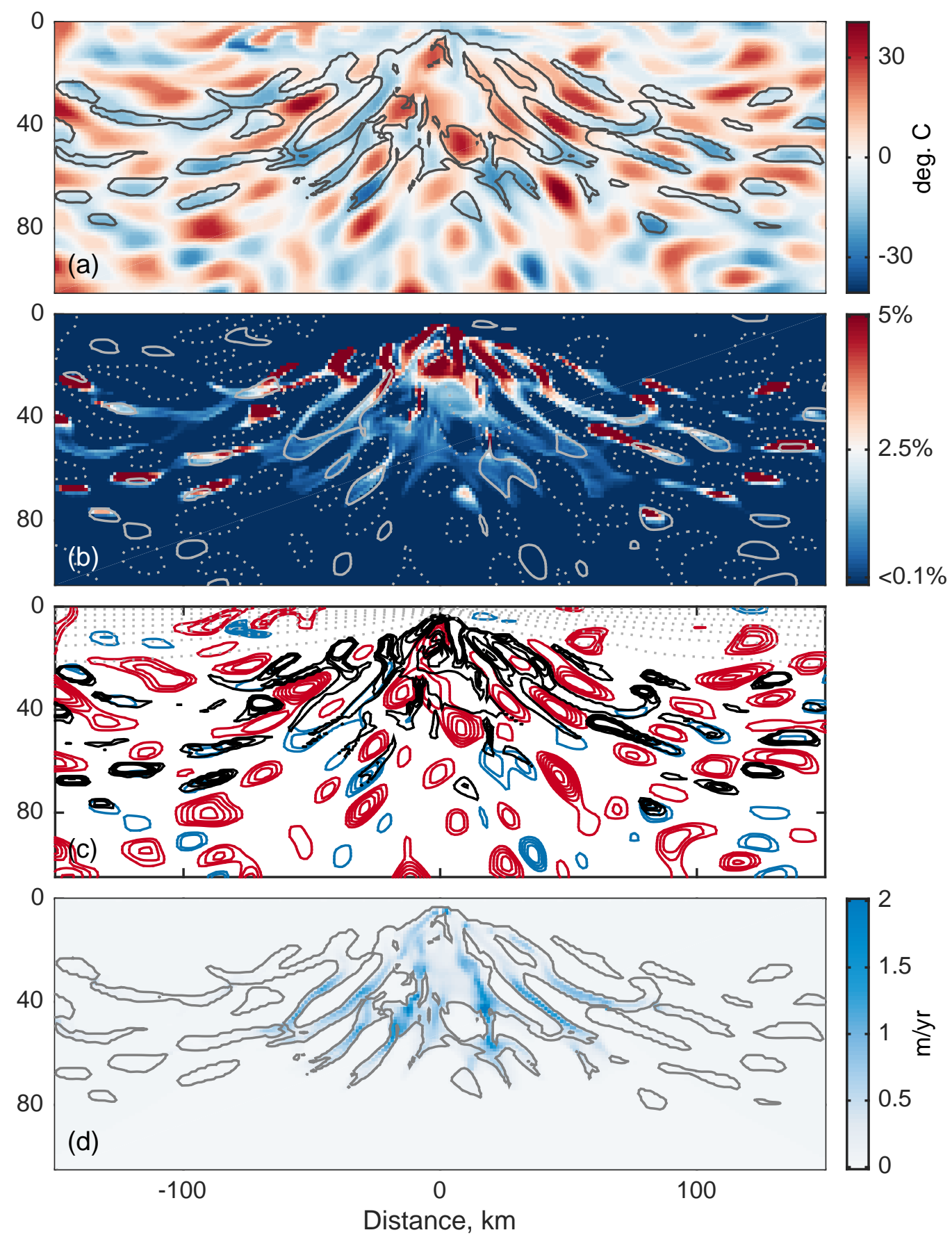

Figure 9: Covariation of porosity and composition from a representative experiment initialized with the smoothed noise heterogeneity model and $U_{0}=6 \mathrm{~cm} / \mathrm{yr}$. (a) Colours show composition in terms of a perturbation to the solidus temperature; grey lines contour $\phi=1 \%$. (b) Colour shows porosity; grey solid lines contour $\Delta T_{C}=-15^{\circ} \mathrm{C}$; grey dotted lines contour $\Delta T_{C}=+10^{\circ} \mathrm{C}$. (c) Covariation of large porosities and regions of enriched and depleted mantle. Black lines contour $\phi=1 \%$, blue lines contour $\Delta T_{C} \leq-15^{\circ} \mathrm{C}$ in $5^{\circ} \mathrm{C}$ intervals, and red 22 lines contour $\Delta T_{C} \geq+10^{\circ} \mathrm{C}$ in $5^{\circ} \mathrm{C}$ intervals. (d) Magma speed $\left|\mathbf{v}_{f}\right|$ with grey lines showing the $0.5 \%$ porosity contour. 
speeds. It is interesting to note that, since the average flow speed for each particle is, in part, a response to local thermodynamic conditions, different heterogeneity configurations could result in speed-composition distributions different to those shown in figures 9r and d.

\subsection{Effects of model parameters}

An important point about the results above is that they are sensitive to the model parameters, and particularly those that directly affect the magma velocity. Appendix B presents a nondimensionalization of equation 1 for $\mathbf{v}_{f}$ and shows that the nondimensionalizing factor is $\mathcal{R}=k_{0} \Delta \rho g / \mu$, where $k_{0}$ is the reference permeability, $\Delta \rho$ is the density difference between the matrix and magma, $g$ is the acceleration due to gravity and $\mu$ is the viscosity of the magma. Of these, $g$ is accurately known, possible values for $\Delta \rho$ vary to within a few percent of the value given in table A1 (500 $\left.\mathrm{kg} \mathrm{m}^{3}\right)$, measurements of $\mu$ span one order of magnitude (1-10 Pa.s, Dingwell (1995)) and estimates of $k_{0}$ lie in the range $10^{-9} \mathrm{~m}^{2}$ to $10^{-4} \mathrm{~m}^{2}$ (Faul, 1997; Wark and Watson, 1998; Faul, 2001; Wark, 2003; Connolly et al., 2009). Uncertainty in these parameters means that the range of plausible values for $\mathcal{R}$ spans some 6 orders of magnitude. For comparison, a permeability constant of $k_{0}=10^{-7} \mathrm{~m}^{2}$ was selected for the model runs above, and the corresponding value of $\mathcal{R}$ lies approximately in the centre of the possible range.

To investigate how the mean particle speed $\left\langle v_{p}\right\rangle$ and travel time $\tau$ vary with $\mathcal{R}$, the model was reconfigured to consider the dynamically simpler case of a column of upwelling, chemically homogenous mantle rock. Figure 10 plots the predicted $\left\langle v_{p}\right\rangle$ and $\tau$ for values of $\mathcal{R}$ that span 5 orders of magnitude. The data are normalized by results from the model run with the parameter regime specified in table A1. The figure shows that $\left\langle v_{p}\right\rangle$ scales with $\mathcal{R}^{1 / n}$ (figure 10a), where $n$ is the permeability exponent and that $\tau$ varies with $\mathcal{R}^{-1 / n}$. This scaling agrees with analysis of the governing equations in one dimension by Hewitt (2010); it indicates that an change in $\mathcal{R}$ by a factor of $10^{3}$ will yield an order of magnitude change in $\left\langle v_{p}\right\rangle$ and $\tau$. Provided that the scaling holds for models with a heterogeneous mantle, setting $\mathcal{R}=10^{3} \mathcal{R}^{*}$ would reduce the average 
Table A1: List of parameters and preferred values.

\begin{tabular}{|c|c|c|}
\hline Symbol & Meaning & Value \\
\hline$\kappa$ & Thermal diffusivity & $1 \times 10^{-6} \mathrm{~m} / \mathrm{s}^{2}$ \\
\hline$L$ & Latent heat of fusion & $5.5 \times 10^{5} \mathrm{~J} / \mathrm{kg}$ \\
\hline$M_{S}$ & Slope $\partial T / \partial C$ of the solidus & $200 \mathrm{~K}$ \\
\hline$M_{L}$ & Slope $\partial T / \partial C$ of the liquidus & $200 \mathrm{~K}$ \\
\hline $\mathcal{T}$ & Potential temperature & $1696 \mathrm{~K}$ \\
\hline$T_{0}$ & $\begin{array}{l}\text { Solidus temperature for reference } \\
\text { mantle at } 0 \mathrm{kbar}\end{array}$ & $1605 \mathrm{~K}$ \\
\hline$C_{0}$ & Reference mantle composition & 0.5 \\
\hline$\Delta C$ & $\begin{array}{l}\text { Difference in composition between } \\
\text { rock and magma in thermodynamic } \\
\text { equilibrium }\end{array}$ & 0.1 \\
\hline$\Delta T$ & Temperature scale & $M \Delta C$ \\
\hline$\Delta \rho$ & Matrix-melt density difference & $500 \mathrm{~kg} / \mathrm{m}^{3}$ \\
\hline$\alpha$ & Coefficient of thermal expansion & $3 \times 10^{-5} \mathrm{~K}^{-1}$ \\
\hline$c_{P}$ & Specific heat capacity & $1200 \mathrm{~J} / \mathrm{kg} / \mathrm{K}$ \\
\hline$\gamma^{-1}$ & Clapeyron slope & $60 \mathrm{~K} / \mathrm{GPa}$ \\
\hline $\mathcal{D}$ & Chemical diffusivity & $1 \times 10^{-8} \mathrm{~m} / \mathrm{s}^{2}$ \\
\hline$g$ & Acceleration due to gravity & $9.8 \mathrm{~m} / \mathrm{s}^{2}$ \\
\hline$k_{0}$ & Reference permeability & $1 \times 10^{-7} \mathrm{~m}^{2}$ \\
\hline$\eta_{\max }$ & Cut-off shear viscosity, maximum & $10^{25} \mathrm{~Pa} \cdot \mathrm{s}$ \\
\hline$\Delta x$ & Grid spacing in $x$-direction & $1.25 \mathrm{~km}$ \\
\hline$\Delta z$ & Grid spacing in $z$-direction & $1.25 \mathrm{~km}$ \\
\hline
\end{tabular}

travel times to order $10^{4}$ years and increase mean flow speeds to order $10 \mathrm{~m} / \mathrm{yr}$. 

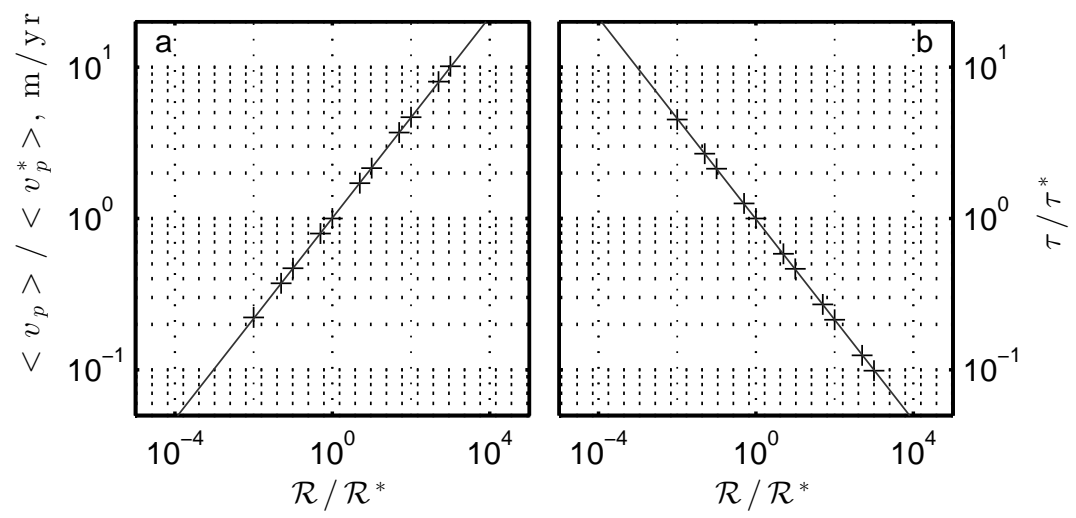

Figure 10: The effect of $\mathcal{R}=k_{0} \Delta \rho g / \mu$ on melt migration computed using the upwelling column model outlined in Weatherley and Katz (2012). The upwelling rate is $6 \mathrm{~cm} / \mathrm{yr}$ and the grid spacing is $1 \mathrm{~km}$. Other parameter values are given in table A1. (a) Effect of $\mathcal{R}$ on the mean particle speed $\left\langle v_{p}\right\rangle$. $\mathcal{R}^{*}$ and $\left\langle v_{p}\right\rangle^{*}$ indicate normalizing values computed from an experiment conducted with the parameter regime in table A1. (b) Effect of $\mathcal{R}$ on the duration of melt migration $\tau$, where $\tau^{*}$ is associated with the $\mathcal{R}^{*}$ parameter regime.

\subsection{Limitations and assumptions}

The results above are also subject to a set of limitations arising from the assumptions that underpin the models and theory. An important assumption is that melt migration is accommodated entirely by porous flow (McKenzie, 1984, Fowler, 1985; Ribe, 1985 ; Bercovici et al., 2001). Whilst a mass of geochemical and geophysical observations require the mantle to be porous and melt to migrate by porous flow (e.g. Johnson et al., 1990; Johnson and Dick, 1992; The MELT Seismic Team, 1998; Sims et al., 1999), several studies also suggest that melt can flow through cracks (Sleep, 1988; Fowler and Scott, 1996; Ito and Martel, 2002; Maalœ, 2003). This mode of magma flow is less well studied than reactive channelisation, thus uncertainty surrounds how widely it applies to the sub-ridge melting region. Nevertheless, magma flow through open cracks can accommodate much faster flow speeds than melt migration through high porosity channels; hence this mode of localisation lends itself well to arguments for preservation of deep-origin ${ }^{210} \mathrm{~Pb}$ disequilibria in zero-age MORB (Rubin et al., 2005). Future models should seek to include a brittle fracture criterion in order to 
assess the implications of fracture for melt extraction.

An additional limitation lies in the two-dimensional description of the dynamics at mid-ocean ridges. This imposes an infinite, out-of-plane length on all heterogeneities and melt migration features in the model and restricts mass and heat transport to be in the plane of the solution. Katz and Weatherley (2012) note that this latter restriction could reduce the efficiency of channel formation. For instance, if a channel has a cylindrical geometry in three dimensions, mass and heat can be supplied from around its circumference. Radial heat and mass transfer could potentially reinforce the channelforming instability, resulting in higher porosities and faster magma flow speeds. Three dimensional consideration of melt migration is also important in the vicinity of ridge offsets. Previous studies show that hot mantle beneath ridge segment ends is cooled by the adjacent, older and cooler lithosphere (Magde and Sparks, 1997; Weatherley and Katz, 2010; Herbert and Montési, 2011). This cooling effect is likely to suppress porosity generation, result in lower magma flow speeds, and focus melt towards segment centres. Exactly how the presence of mantle heterogeneity might modify melting and melt transport close to segment ends is not yet understood, but could have particular relevance to the interpretation of bull's eye gravity anomaly patterns along highly segmented ridges, such as the Mid-Atlantic Ridge (Kuo, 1988; Lin et al., 1990; Detrick et al., 1995; Magde and Sparks, 1997).

The petrological model is the most significant simplification in our theoretical framework for magma flow. Motivated by experimental studies of mantle rocks, the model captures variation of the mantle solidus with composition and pressure, and takes an energetically consistent approach to melting by decompression and reaction. These properties approximately align the model with natural system. For simplicity, however, the model system comprises two phases and two thermodynamic components. Whilst this precludes consideration of additional important petrological features of the subridge mantle, such as variations in modal mineralogy, volatiles, phase specific enthalpies of fusion, and reactive precipitation of pyroxene, it lends itself well to elucidating the dynamical consequences of mantle heterogeneity for melt migration. A particularly im- 
portant result of the counterpart models by Weatherley and Katz (2012) and Katz and Weatherley (2012) is that the arrangement and existence of melt migration pathways is a response to local thermodynamic effects. This finding is expected to hold both on smaller length scales and in simulations with an expanded petrological model; thus the current model provides a reasonable, first order description of the large scale dynamical behaviour. However, a more detailed consideration of the petrology may offer new insights to trace element redistribution and generation of U-series disequilibria in the melting region.

Similar to earlier models by Katz (2010), magma is extracted at the ridge axis. The internal boundary that facilitates melt extraction is carefully tuned so that on time scales that are long compared to a time step, the rate of magma production approximately matches the combined rates of melt extraction at the ridge, freezing at the base of the lithosphere and exit of magma through the side walls of the domain. One consequence of this internal boundary is a slight build-up of magma in the top 20 $\mathrm{km}$ of the mantle beneath the ridge axis. In this region, the dynamic pressure gradients are such that the magma velocity is small, despite the large porosity. Regions of high porosity are also predicted to occur in isolated patches in the flanks of the melting region. Since the permeability increases as a power-law of porosity, magma within these regions can convect at speeds of hundreds of metres per year, drastically reducing the size of the time-step in the simulations. To avoid this, the permeability is capped at a value corresponding to a porosity of $10 \%$. For the most part, the permeability cap has negligible effect on the speed of melt migration within channels. It also has negligible effect on magma speeds in the region of slightly higher porosity immediately beneath the ridge axis, owing to the setup of the internal boundary condition for melt extraction.

An additional limitation of the model is the grid resolution. In the simulations above, the grid resolution is $1.25 \mathrm{~km}$, which limits the smallest length scale of heterogeneity and width of melt localization features. A key result of the counterpart models by Weatherley and Katz (2012) and Katz and Weatherley (2012) is that the arrangement 
and existence of melt migration pathways is response to local thermodynamic effects. Therefore, it is reasonable to expect a similar basic model behaviour in simulations run with much finer grid resolution. Alongside offering opportunities to explore the coupling between heterogeneity on sub-kilometer scales and magma flow speeds, finer resolution models offer greater possibilities for investigating how the number density of fusible and refractory heterogeneities influence the large scale pattern of melt migration. Many studies of ophiolites and peridotite massifs demonstrate that mineralogical heterogeneity can be present on scales upwards of a few centimetres (e.g. Boudier and Coleman, 1981; Gregory, 1984; Reisberg et al., 1991; Blichert-Toft et al., 1999; Le Roux et al., 2007). At these small scales, physical attributes of the mantle such as grain size variations and minor shear zones are likely to have consequences for melt localization, in addition to those from composition heterogeneity. Our understanding of how these different variables influence the dynamics of magma flow and hence the time scale of melt migration will benefit from future studies that combine lithological and structural mapping of mantle peridotites on a range of scales with higher resolution numerical models with more advanced rheological laws than that used here.

\subsection{Geochemical implications}

A major scientific challenge at present is to understand the chemistry of oceanic basalts in terms of source composition and processes that affect magmas between the point of origin and eruption. A key result from the models above is that under conditions of strong mantle heterogeneity, melts migrate to the ridge axis on a broad range of time scales. We postulate that (i) this distribution in travel times maps on to significant natural variability in the U-series disequilibria observed along MORs, and (ii) that the results offer an explanation for the decoupling that is often observed between Useries disequilibria and other geochemical data, even in settings where there is evidence for mineralogical source heterogeneity (e.g. Kokfelt et al., 2003, Bourdon et al., 2005, Stracke et al., 2003; Prytulak and Elliott, 2009; Russo et al., 2009; Koorneef et al., 2012).

To further understand the implications of these results, future studies should aim to 
constrain how properties of mantle heterogeneity and the melt transport network are linked. Possible avenues to investigate include how the number density, fusibility and connectedness of heterogeneity relate to the topology and tortuosity of melt channels, whether channel tortuosity on smaller scales than that examined here has a significant effect on melt transport time, and how heterogeneity and magma flow together affect the rate of magma supply to ridges, and by extension their morphology.

Within the context of the model results, it is also important to consider other processes that can have notable implications for the geochemistry of oceanic basalts. Among the most significant is mixing. Analyses of whole rock and melt inclusion chemistry by Maclennan et al. (2003) and Maclennan (2008) demonstrate that erupted magmas are mixtures of many small batches of melt, with up to 30 batches of melt represented in a single hand specimen. Additionally, Rudge et al. (2013) showed that the mixing process is nonuniform with depth, with the deepest melts appearing to be more homogenized than shallower melts. Interestingly, they also found that compositional arrays produced during mixing do not necessarily point towards the isotopic compositions of the source materials. A second set of processes important to the the preservation or homogenisation of primary melt compositions are those that occur in the crust and uppermost mantle. Rubin and Sinton (2007) showed that high melt supply rates (typically associated with fast spreading ridges) promote larger and shallower accumulations of cooler magma, longer residence times in sub-ridge magma reservoirs, and consequently greater extents of homogenization and differentiation. In contrast, lower melt supply rates promote episodic magma accumulation in hotter, more poorly connected magma reservoirs, and erupted products that show high degrees of chemical variability and lower degrees of differentiation. In the shallow crust, crystallisation processes and melt-rock reaction can obfuscate the relationship between primary melt chemistry and that of erupted magmas (e.g. Van Orman et al., 2006; Maclennan, 2008). However, Rubin et al. (2009) note that few sections of the MOR system are sampled at high enough resolution to quantify how these processes, and by extension, results of numerical models, relate to MORB compositions and MOR structure. 
Despite these additional complexities and limitations, the results above also have several general implications for our understanding of how theories of magma flow relate to observations of U-series disequilibria in MORB. Under the parameter regime outlined in table A1, the results indicate that magma flow in a heterogeneous mantle is most commonly fast enough to preserve ${ }^{230} \mathrm{Th}$ excesses generated deep in the melting region. Some particles travel slowly enough for ${ }^{230} \mathrm{Th}$ initial excesses to decay to zero. However, significant excesses for these particles could be generated by ingrowth, or alternatively, their lack of ${ }^{230} \mathrm{Th}$ disequilibrium could be obscured by mixing. For the same simulations, magma flow too slow to preserve deep-origin ${ }^{226}$ Ra disequilibria, yet section 4.3 suggests that under less moderate parameter regimes, the models will predict flow speeds sufficiently fast to enable attribution of some ${ }^{226}$ Ra disequilibria to a deep source. Under even the most favourable parameter regime, the current theoretical framework for porous melt migration is incapable of preserving ${ }^{210} \mathrm{~Pb}$ disequilibria generated within the melting region.

To clarify this situation, and to address whether current theory can account for ${ }^{226} \mathrm{Ra}$ disequilibria, future studies must consider the full range of disequilibrium-generating processes. These include chromatographic fractionation, ingrowth, degassing and diffusive partitioning between melt and cumulate rocks. Furthermore, the models must also be able to account for covariation of different parent-daughter nuclide pairs. Models by Jull et al. (2002) suggest that magmas from different portions of the melting region must mix to produce the observed signature, and Elliott and Spiegelman (2003) demonstrate that so called 'full reactive transport models', which couple equations for element concentration to dynamical models similar to those described above, also predict an inverse relationship between ${ }^{226} \mathrm{Ra}$ and ${ }^{230} \mathrm{Th}$ disequilibria, but fail to match the observed amplitudes. However, future modelling studies that consider U-series disequilibria in the context of mantle heterogeneity and the physics of melt migration may yield a more conclusive view on the presence of short-lived U-series disequilibria in oceanic basalts. 


\section{Conclusions}

Results from energetically consistent models of magma flow show that plate spreading and mantle heterogeneity have important consequences for the time scale of melt migration beneath ridges. Heterogeneity perturbs the thermal structure of the mantle that is established by plate spreading, and causes magma flow to localize into high porosity channels. Magma flows relatively rapidly through channels directly beneath the ridge axis where the upwelling rate of the porous mantle is greatest, and more slowly through channels on the flanks of the melting region. Flow speeds also increase with spreading rate, consistent with simpler models. The main effect of mantle heterogeneity on the time scale of magma flow is realised through the formation of high porosity channels. However, magma flow is generally slower in more enriched and more depleted regions, and faster in regions of close to average fusibility.

Our findings suggest that the mean speed of channelized flow in a heterogeneous mantle is approximately $20 \%$ faster than diffuse flow in a homogenous mantle. For the parameter regime and spreading rates considered, individual packets of magma in a single simulation migrate to the ridge axis on time scales as short as $25 \mathrm{kyr}$ and as long as $350 \mathrm{kyr}$, with mean speeds between 0.2 and $1.3 \mathrm{~m} / \mathrm{yr}$. Scaling analysis suggests that for plausible parameter regimes that capture a more permeable mantle, the duration of melt migration might be reduced by a factor of 10 . These speeds are sufficient for mineral-melt partitioning deep in the melting region to contribute to ${ }^{230} \mathrm{Th}$ and, in some circumstances even ${ }^{226} \mathrm{Ra}$ disequilibria observed in MORB. However, the models' inability to explain observations of ${ }^{210} \mathrm{~Pb}$ deficits in MORB suggests that current theories of porous melt migration do not comprehensively describe the physics of magma flow.

An important result is that mantle heterogeneity induces significant natural variability in U-series disequilibria preserved in MORB, and thus the models offer one explanation as to why observations are often decoupled from other geochemical signals and properties of ridge axes, even in situations where there is good evidence for 
mineralogical heterogeneity in the mantle.

Acknowledgements. We wish to thank J. Maclennan and I. Hewitt for interesting discussions, and K. Rubin and A. Stracke for useful reviews; all of which helped to improve this manuscript. Oxford Supercomputing Centre, a former incarnation of the Advanced Research Computing facility at the University of Oxford is acknowledged for providing compute time, HPC resources and technical support. SW thanks the Danish Council for Independent Research for generous funding whilst writing this manuscript. RK thanks the Leverhulme Trust for support

\section{Appendix A. Parameter Values}

The parameter values used for the numerical experiments above are listed in table A1, below.

\section{Appendix B. Nondimensionalization}

To nondimensionalize equation 1 the following scales are employed:

$$
\begin{gathered}
\left(\mathbf{v}_{f}^{\prime}, \mathbf{v}_{m}^{\prime}\right)=w_{0}\left(\mathbf{v}_{f}, \mathbf{v}_{\mathbf{m}}\right), \\
K^{\prime}=k_{0} K, \\
\nabla^{\prime}=\frac{1}{H} \nabla \\
P_{d}=\Delta \rho g H P_{d},
\end{gathered}
$$

where nondimensional variables are indicated with a prime, $H$ is the height of the domain and $k_{0}$ is the reference permeability. Application of these scales reveals that equation 1 is nondimensionalized by the factor $\mathcal{R}=k_{0} \Delta \rho g / \mu$. 


\section{References}

Aharonov, E., Whitehead, J., Kelemen, P., Spiegelman, M., 1995. Channeling instability of upwelling melt in the mantle. Journal of Geophysical Research 100 (B10), $20433-20450$.

Allègre, C., Turcotte, D., 1986. Implications of a 2-component marble-cake mantle. Nature 323 (6084), 123-127.

Batchelor, G., 1967. An introduction to fluid dynamics. Cambridge University Press, Cambridge.

Bear, J., 1972. Dynamics of fluids in porous media. Dover, New York.

Bercovici, D., Ricard, Y., Schubert, G., 2001. A two-phase model for compaction and damage 1. General Theory. Journal of Geophysical Research 106, 8887-8906.

Blichert-Toft, J., Albarède, F., Kornprobst, J., 1999. Lu-Hf isotope systematics of garnet pyroxenites from Beni Bousera, Morocco: Implications for basalt origin. Science $283,1303-1306$.

Boudier, F., Coleman, R., 1981. Cross section through peridotite in the Samail Ophiolite, Southeastern Oman Mountains. Journal of Geophysical Research 86, 2573-2592.

Bourdon, B., Turner, S., Ribe, N., 2005. Partial melting and upwelling rates beneath the Azores from a U-series isotope perspective. Earth and Planetary Science Letters 239 (1-2), 42-56.

Connolly, J., Schmidt, M., Solferino, G., Bagdassarov, N., 2009. Permeability of asthenospheric mantle and melt extraction rates at mid-ocean ridges. Nature 462, 209212.

Costa, A., 2006. Permeability-porosity relationship: A reexamination of the KozenyCarman equation based on a fractal pore-space geometry assumption. Geophysical Research Letters 33, L02318. 
Detrick, R., Needham, H., Renard, V., 1995. Gravity anomalies and crustal thickness variations along the Mid-Atlantic Ridge between $33^{\circ} \mathrm{N}$ and $40^{\circ} \mathrm{N}$. Journal of Geophysical Research 100 (B3), 3767-3787.

Dingwell, D., 1995. Viscosity and anelasticity of melts. In: Ahrens, T. (Ed.), Mineral Physics and Crystallography: A Handbook of Physical Constants. Vol. 2 of AGU Reference Shelf. AGU, Washington, pp. 209-217.

Elliott, T., Spiegelman, M., 2003. Melt Migration in Oceanic Crustal Production: A U-series Perspective. In: Editors-in Chief: Holland, H., Turekian, K. (Eds.), Treatise on Geochemistry. Vol. 3. Pergamon, Oxford, Ch. 14, pp. 465-510.

Elliott, T., Spiegelman, M., 2014. Melt migration in oceanic crustal production: A Useries perspective. In: Turekian, H., Holland, K. (Eds.), Treatise on Geochemistry, second edition Edition. Elsevier, Oxford, Ch. 4.15, pp. 543-581.

Faul, U., 1997. Permeability of partially molten upper mantle rocks from experiments and percolation theory. Journal of Geophysical Research 102, 10299-10311.

Faul, U., 2001. Melt retention and segregation beneath mid-ocean ridges. Nature 410, $920-923$.

Fowler, A., 1985. A mathematical model of magma transport in the asthenosphere. Geophysical and Astrophysical Fluid Dynamics 33, 63-96.

Fowler, A., Scott, D., 1996. Hydraulic crack propagation in a porous medium. Geophysical Journal International 127, 595-604.

Gregory, R., 1984. Melt percolation beneath a spreading ridge: Evidence from the Semail peridotite, Oman. Geological Society of London Special Publications 13, 5562.

Herbert, L., Montési, L., 2011. Melt extraction pathways at segmented mid-ocean 
ridges: Application to the East Pacific Rise at the Siqueiros transform. Geophysical Research Letters 38, L11306.

Hesse, M., Schiemenz, A., Liang, Y., Parmentier, E., 2011. Compaction-dissolution waves in an upwelling mantle column. Geophysical Journal International 187, 10571075 .

Hewitt, I., 2010. Modelling melting rates in upwelling mantle. Earth and Planetary Science Letters 300, 264-274.

Hirschmann, M., Stolper, E., 1996. A possible role for garnet pyroxenite in the origin of the "garnet signature" in MORB. Contributions to Mineralogy and Petrology 124 (2), $185-208$.

Ito, G., Martel, S., 2002. Focusing of magma in the upper mantle through dike interaction. Journal of Geophysical Research 107, 2223.

Johnson, K., Dick, H., 1992. Open system melting and temporal and spatial variation of peridotite and basalt at the Atlantis II fracture zone. Journal of Geophysical Research 97, 9219-9241.

Johnson, K., Dick, H., Shimizu, N., 1990. Melting in the oceanic upper mantle: an ion microprobe study of diopsides in abyssal peridotites. Journal of Geophysical Research 95 (B3), 2261-2678.

Jull, M., Kelemen, P., Sims, K., 2002. Consequences of diffuse and channelled porous melt migration on uranium series disequilibria. Geochimica and Cosmochimica Acta $66,4133-4148$.

Kaneshima, S., Helffrich, G., 1999. Dipping low-velocity layer in the mid-lower mantle: Evidence for geochemical heterogeneity. Science 283, 1888-1891.

Kaneshima, S., Helffrich, G., 2003. Subparallel dipping heterogeneities in the mid-lower mantle. Journal of Geophysical Research 108, 2272. 
Katz, R., 2008. Magma dynamics with the Enthalpy Method: Benchmark solutions and magmatic focusing at mid-ocean ridges. Journal of Petrology 49, 2099-2121.

Katz, R., Weatherley, S., 2012. Consequences of mantle heterogeneity for melt extraction at mid-ocean ridges. Earth and Planetary Science Letters 335-336, 226-237.

Katz, R. F., 2010. Porosity-driven convection and asymmetry beneath mid-ocean ridges. Geochemistry, Geophysics, Geosystems 11, Q0AC07.

Kelemen, P., 1990. Reaction between ultramafic rock and fractionating basaltic magma I. Phase relations, the origin of calc-alkaline magma series, and the formation of discordant dunite. Journal of Petrology 31, 51-98.

Kelemen, P., Hirth, G., Shimizu, N., Spiegelman, M., Dick, H., 1997. A review of melt migration processes in the adiabatically upwelling mantle beneath oceanic spreading ridges. Philosophical Transactions of the Royal Society A 355 (1723), 283-318.

Kelemen, P., Shimizu, N., Salters, V., 1995. Extraction of mid-ocean ridge basalt from the upwelling mantle by focused flow of melt in dunite channels. Nature 375, 747-753.

Kellogg, L., Turcotte, D., 1990. Mixing and the distribution of heterogeneities in a chaotically convecting mantle. Journal of Geophysical Research 95, 421-432.

Kokfelt, T., Hoernle, K., Hauff, F., 2003. Upwelling and melting of the Iceland plume from radial variation of ${ }^{238} \mathrm{U}_{-}{ }^{230} \mathrm{Th}$ disequilibria in postglacial volcanic rocks. Earth and Planetary Science Letters 214, 167-186.

Koorneef, J., Stracke, A., Bourdon, B., Grönvold, K., 2012. The influence of source heterogeneity on the U-Th-Pa-Ra disequilibria in post-glacial tholeiites from Iceland. Geochimica et Cosmochimica Acta 87, 243-266.

Kuo, B.-Y. amd Forsyth, D., 1988. Gravity anomalies of the ridge-transform system in the South Atlantic between 31 and $34.5^{\circ} \mathrm{S}$ : Upwelling centres and variations in crustal thickness. Marine Geophysical Researches 10, 205-232. 
Le Roux, V., Bodinier, J., Tommasi, A., Alard, O. amd Dautria, J., Vauchez, A., Riches, A., 2007. The Lherz spinel lherzolite: Refertilized rather than pristine mantle. Earth and Planetary Science Letters 259, 599-612.

Liang, Y., Guo, Y., 2003. Reactive dissolution instability driven by chemical diffusion with applications to harzburgite reactive dissolution. Geophysical Research Letters $30(13), 1722$.

Liang, Y., Schiemenz, A., Hesse, M., Parmentier, E., Hesthaven, J., 2010. High-porosity channels for melt migration: Top is the dunite and bottom is the harzburgite and lherzolite. Geophysical Research Letters 37, L15306.

Lin, J., Purdy, G., Schouten, H., Sempere, J., Zervas, C., 1990. Evidence from gravity data for focused magmatic accretion along the Mid-Atlantic Ridge. Nature 244, 627632.

Liu, C., Snow, J., Hellebrand, E., Brügmann, G., von der Handt, A., Büchl, A., Hofmann, A., 2008. Ancient, highly heterogeneous mantle beneath Gakkel ridge, Arctic Ocean. Nature 452, 311-361.

Lundstrom, C., 2000. Models of U-series disequilibria generation in MORB: the effects of two scales of porosity. Physics of earth and Planetary Interiors 121, 189-204.

Lundstrom, C., Chaussidon, M., Hsui, A., Kelemen, P., Zimmerman, M., 2005. Observations of $\mathrm{Li}$ isotopic variations in the Trinity Ophiolite: Evidence for isotopic fractionation by diffusion during mantle melting. Geochimica et Cosmochimica Acta $69,735-751$.

Lundstrom, C., Gill, J., Williams, Q., Hanan, B., 1998. Investigating solid mantle upwelling beneath mid-ocean ridges using U-series disequilibria: II. A local study at 33 degrees mid-Atlantic ridge. Earth and Planetary Science Letters 157, 167-181.

Lundstrom, C., Gill, J., Williams, Q., Perfit, M., 1995. Mantle melting and basalt extraction by equilibrium porous flow. Science 270, 1958-1961. 
Maalœ, S., 2003. Melt dynamics of partially molten mantle with randomly oriented veins. Journal of Petrology 44, 1193-1210.

Maclennan, J., 2008. Lead isotope variability in olivine-hosted melt inclusions from Iceland. Geochimica et Cosmochimica Acta 72, 4159-4176.

Maclennan, J., McKenzie, D., Hilton, F., Grönvold, K., Shimizu, N., 2003. Geochemical variability in a single flow from northern Iceland. Journal of Geophysical Research 108 (B1), 2007.

Magde, L., Sparks, S., 1997. Three-dimensional mantle upwelling, melt generation, and melt migration beneath segmented slow spreading ridges. Journal of Geophysical Research 102, 20571-20583.

McKenzie, D., 1984. The generation and compaction of partially molten rock. Journal of Petrology 25 (3), 713-765.

McKenzie, D., 1985. ${ }^{230} \mathrm{Th}^{2}{ }^{238} \mathrm{U}$ disequilibrium and the melting processes beneath ridge axes. Earth and Planetary Science Letters 72, 149-157.

McKenzie, D., 2000. Constraints on melt generation and transport from U-series activity ratios. Chemical Geology 161, 81-94.

Ortoleva, P., Chadam, J., Merino, E., Sen, A., 1987. Geochemical self-organisation II: The reactive-infiltration instability. American Journal of Science 287, 1008-1040.

Prytulak, J., Elliott, T., 2009. Determining melt productivity of mantle sources from ${ }^{238} \mathrm{U}-{ }^{230} \mathrm{Th}$ and ${ }^{235} \mathrm{U}-{ }^{231} \mathrm{~Pa}$ disequilibria; an example from Pico Island, Azores. Geochimica et Cosmochimica Acta 73, 2103-2122.

Reisberg, L., Allègre, C., Luck, J.-M., 1991. The Re-Os systematics of the Ronda ultramafic complex of southern Spain. Earth and Planetary Science Letters 105, 196213. 
Ribe, N., 1985. The deformation and compaction of partial molten zones. Geophysical Journal of the Royal Astronomical Society 83, 497-501.

Rubin, K., MacDougall, J., 1988. ${ }^{226}$ Ra excesses in mid-ocean ridge basalts and mantle melting. Nature 355, 158-161.

Rubin, K., Sinton, J., 2007. Inferences on mid-ocean ridge thermal and magmatic structure from MORB compositions. Earth and Planetary Science Letters 260 (1-2), 257276.

Rubin, K., Sinton, J., Maclennan, J., Hellebrand, E., 2009. Magmatic filtering of mantle compositions at mid-ocean ridge volcanoes. Nature Geoscience 2, 321-328.

Rubin, K., van der Zander, I., Smith, M., Bermmanis, E., 2005. Minimum speed limit for ocean ridge magmatism from ${ }^{210} \mathrm{~Pb}^{226} \mathrm{Ra}^{-230} \mathrm{Th}$ disequilibria. Nature 437, 534538.

Rudge, J., Maclennan, J., Stracke, A., 2013. The geochemical consequences of mixing melts from a heterogeneous mantle. Geochimical et Cosmochimica Acta 114, 112-143.

Russo, C., Rubin, K., Graham, D., 2009. Mantle lithology and magma supply to the Southeast Indian Ridge: The roles of lithology and melting conditions from U-series disequilibria. Earth and Planetary Science Letters 278, 55-66.

Schiemenz, A., Liang, L., Parmentier, E., 2011. A high-order numerical study of reactive dissolution in an upwelling heterogeneous mantle-I. Channelization, channel lithology and channel geometry. Geophysical Journal International 186, 641-664.

Shorttle, O., Maclennan, J., 2011. Compositional trends of Icelandic basalts: Implications for short-length scale lithological heterogeneity in mantle plumes. Geochemistry, Geophysics, Geosystems 12 (11), Q11008.

Sims, K., DePaolo, D., Murrell, M., Baldridge, W., Goldstein, S., Clague, D., Jull, M., 1999. Porosity of the melting zone and variations in the solid mantle upwelling 
rate beneath Hawaii: Inferences from ${ }^{238} \mathrm{U} \_{ }^{230} \mathrm{Th}-{ }^{226} \mathrm{Ra}$ and ${ }^{235} \mathrm{U} \_{ }^{231} \mathrm{~Pa}$ disequilbria. Geochimica et Cosmochimica Acta 63, 4119-4138.

Sleep, N., 1988. Tapping of melt by veins and dykes. Journal of Geophysical Research 93, 10255-10272.

Sobolev, A., Hofmann, A., Brügmann, G., Batanova, V., Kuzmin, D., 2008. A quantitative link between recycling and osmium isotopes. Science 321, 536.

Sparks, D., Parmentier, E., 1991. Melt extraction from the mantle beneath spreading centres. Earth and Planetary Science Letters 105, 386-377.

Spiegelman, M., Kelemen, P., 2003. Extreme chemical variability as a consequence of channelized melt transport. Geochemistry, Geophysics, Geosystems 4 (7), 1055.

Spiegelman, M., Kelemen, P., Aharonov, E., 2001. Causes and consequences of flow organization during melt transport: the reaction infiltration instability in compactible media. Journal of Geophysical Research 106, 2061-2077.

Spiegelman, M., Kenyon, P., 1992. The requirements for chemical disequilibrium during magma migration. Earth and Planetary Science Letters 109, 611-620.

Spiegelman, M., McKenzie, D., 1987. Simple 2D models for melt extraction at midocean ridges and island arcs. Earth and Planetary Science Letters 83, 137-152.

Stracke, A., Bourdon, B., McKenzie, D., 2006. Melt extraction in the Earth's mantle: Constraints from U-Pa-Ra studies in oceanic basalts. Earth and Planetary Science Letters 244, 97-112.

Stracke, A., Zindler, A., Salters, V., McKenzie, D., Grönvold, K., 2003. The dynamics of melting beneath Theistareykir, northern Iceland. Geochemistry, Geophysics, Geosystems 4, 8513.

The MELT Seismic Team, 1998. Imaging the deep seismic structure beneath a midocean ridge: the MELT experiment. Science 280, 1215-1218. 
Turcotte, D., Schubert, G., 2002. Geodynamics. Cambridge University Press, Cambridge.

Turner, S., Bourdon, B., 2010. Melt transport from the mantle to the crust — Uranium series isotopes. In: Dosseto, A., Turner, S., van-Orman, J. (Eds.), Timescales of magmatic processes: From core to atmosphere. Wiley, pp. 210-115.

Van Orman, J., Saal, A., Bourdon, M., Hauri, E., 2006. Diffusive fractionation of Useries nuclides during mantle melting and shallow level melt-cumulate interaction. Geochimica et Cosmochimica Acta 70, 4797-4812.

Wark, D., 2003. Reassessment of pore shapes in microstructurally equilibrated rocks, with implications for permeability of the upper mantle. Journal of Geophysical Research 108, 2050.

Wark, D., Watson, B., 1998. Grain-scale permeabilities of texturally equilibrated, monomineralic rocks. Earth and Planetary Science Letters 164, 591-605.

Weatherley, S., 2013. Melting and melt migration in chemically heterogeneous upwelling mantle. Ph.D. thesis, University of Oxford, www.

Weatherley, S., Katz, R., 2010. Plate-driven mantle dynamics and global patterns of mid-ocean ridge bathymetry. Geochemistry, Geophysics, Geosystems 11, Q10003.

Weatherley, S., Katz, R., 2012. Melting and channelized magmatic flow in heterogeneous, upwelling mantle. Geochemistry, Geophysics, Geosystems 13, Q0AC18.

Wood, D., 1979. A variably veined suboceanic upper mantle-Genetic significance for mid-ocean ridge basalts from geochemical evidence. Geology 7 (10), 499-503.

Yaxley, G., Green, D., 1998. Reactions between eclogite and peridotite: mantle refertilisation by subduction of oceanic crust. Schweizerische mineralogische und petrographische Mitteilungen 78, 243-255. 
Yinting, L., Meissner, R., Theilen, R., Xue, E., 1991. Melt extraction from partially molten regions beneath mid-ocean ridges. Earth and Planetary Science Letters 103, 69-78. 